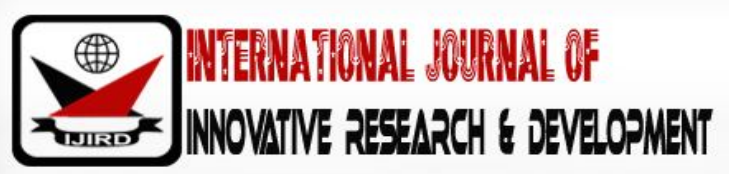

ISSN 2278 - 0211 (Online)

\section{Firms' Behaviour on Open Innovation: A Recipe for Resilience in a Knowledge Driven Business Environment}

\author{
Continue Anddison Eketu \\ Senior Lecturer, Department of Management, University of Port Harcourt, Nigeria \\ Immamuel Emeka \\ Ph.D. Student, Department of Management, Rivers State University, Port Harcourt, Nigeria \\ Wilson Ofoegbu Chukwuemeka \\ Ph.D. Student, Department of Management, University of Port Harcourt, Nigeria
}

\begin{abstract}
:
As the business environment becomes increasingly dynamic and critically complex, survival of the firm is vehemently threatened, on the complex and dynamic interplay of threats and opportunities. This paper extricates the survival behavioural tendencies of the firm, which found expression in open innovation', as an adaptive approach to adjust to external changes, using internal capabilities. The paper identifies open innovation as a knowledge resource apparatus, which involves a teleologic interchange and interactions on knowledge to accelerate the firm's innovative capabilities to expand market opportunities. The paper further identifies that the fundamental organizational level behaviour characteristic that enhances open innovation possibilities is the organizational structural pattern and the enabling or permissive organizational culture. The paper concludes that the survival of the firm amidst the apparent 'certain uncertainties' in the environment depends largely on open innovation as a negative entropic behaviour of the firm. The paper also contends that until the firm is innovative in all spheres of its operations, it survival will be continually threatened.
\end{abstract}

Keywords: Open innovation, firm's resilient behaviour, organizational structure, organizational culture organizational interaction.

\section{Introduction}

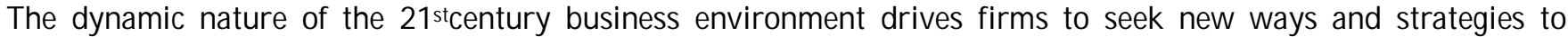
delivering quality products in order to achieve and maintain a competitive edge, customer loyalty, and ultimately, business success. As Nonaka and Tekeuchi (1995) has said, 'in an economy where the only certainty is uncertainty, products proliferate, technology becomes obsolete overnight, and markets shift, the companies that can survive are companies that are knowledge driven and can manage knowledge". For most companies, the process of creating new, innovative products and getting them out the door starts with tapping the most talented members of the R\&D team. Once they have arrived at an idea and found it feasible, R\&D moves to determining the most effective way to develop it and bring it to the market. It sounds logical, but what if there was a way to reinvent the process and bring better products to market the faster and at a lower cost?

Sawhney and Prandeli (2000), identify a predominant trend in their argument that "In the network economy, no firm is an island. On the one hand, the knowledge required to compete in technology markets is becoming more diverse as markets converge and industries collide. On the other hand, firms are narrowing their knowledge base in an effort to specialize and focus. In such business environment, firms can no longer produce and manage knowledge autonomously. They need to cooperate with their trading partners and customers to create knowledge". Kaplan (2011) has said, that, "The new innovation paradigm requires a dramatic shift in the attitude of companies and individuals towards innovation. This shift in attitude is no longer an option for many industries. The forces of change that come with globalization and more demanding customers are here to stay. For many companies it is now a matter of survival. Yet this new landscape also brings great opportunity, at a level never before imagined". The theory of Open Innovation could be the solution, the pathway in this 21 stcentury, characterized by turbulence, and unpredictable economic and business complexities, as it is capable of remolding the behaviour of organizations within the context of business.

According to Chesbrough (2003), as quoted in open innovation, Open Innovation is a paradigm that assumes that firms can and should use external ideas as well as internal ideas, and internal and external paths to market, as the firms look to advance their technology". He adds, that "the boundaries between a firm and its environment have become more permeable: 
innovations can easily be transferred inward and outward. The central idea behind open innovation is that in a world of widely distributed knowledge, companies cannot afford to rely entirely on their own research, but should instead buy or license processes or inventions (i.e. patents) from other companies. In addition, internal inventions not being used in a firm's business should be taken outside the company (e.g. through licensing, joint ventures or spin-offs)".Open innovation means that the company needs to open up its solid boundaries to let valuable knowledge flow in from the outside in order to create opportunities for cooperative innovation processes with partners, customers and/or suppliers. It also includes the exploitation of ideas in order to bring them to market faster than the competitors. Cheshrough et al., consider the open innovation model as the antithesis of the traditional, vertically integrated model wherein internal research and development $(R \& D)$ efforts of a firm lead to products developed internally and distributed thereafter (Chesbrough, Vanhaverbeke\& West, 2006) as quoted in Naqshbandi and Kaur (2011).

Open innovation principles therefore, describe how to deal best with strategic assets in order to meet market demands and company requirements. These definitions point towards the redesigning of the policy, nature, and workings of the $R \& D$ department of firms, such that valuable input can be made from outside the organization and R\&D departments to organizational processes that deliver the best of services and achieve success based on predetermined goals.

In discussing behavior of organizations, we are looking at the organization as an entity. In other words, we are discussing the entire organization as a unit of analysis within the nexus of its behaviour and interactions. Just as individuals and groups have behaviour, so do organizations. At the individual and group levels of analysis, there are identifiable behaviour traits or patterns that are peculiar to the individual(s) and groups. These patterns have their roots in such identified concepts such as learning, values, attitude, perception, and personality. Behaviour at the organizational level also has its roots in concepts that have been identified as the pillars that hold the organization, especially within the context of behaviour. These are the structure and culture of the organization, as cognitive systems.This paper attempts to explore the theory of Open Innovation, highlighting its processes, relating it to behaviour of organizations, with particular reference to how its adoption is impacted by organizational structure and culture. It adopts a prescriptive approach, as it suggests to organizations to embrace the practice of open innovation and make structural and cultural adjustments that are compatible with its practice.

\section{Open Innovation}

As quoted in Fredberg et al., (2008), Chesbrough has defines open innovation as the use of purposive inflows and outflows of knowledge to accelerate internal innovation and expand the markets for external use innovation, respectively.Open innovation assumes that enterprises can and should use external ideas as well as internal ideas, and internal and external ideals to market, to discover and realize innovative opportunities. The Open Innovation model can be compared to the traditional, closed model in which enterprises generate, develop and market their own ideas, usually organized in an internal R\&D department. This closed model has become outdated due to increased mobility of workers, better education, growing presence of venture capital, increasingly shortened product life cycles, growing competition, and wide availability of knowledge from multiple sources. In the Open Innovation model, enterprises can still initiate and nurture innovations within the borders of their organizations, but they may also draw on alternative pathways to bring ideas to the market and to benefit from external knowledge. (de Jong, Vanhavcrheke, Kalvet, Cheshrough (2008).

Gassmann and Enkel (2000) argued that, "Open Innovation is a phenomenon that has become increasingly important for both practice and theory over the last few years.... The recent era of open innovation started when practitioners realized that companies that wished to commercialize both their own ideas as well as other firms' innovation should seek new ways to bring their in-house ideas to market. They need to deploy pathways outside their current businesses and should realize that the locus where knowledge is created does not necessarily always equal the locus of innovation- they need not both be found within the company". This suggests that neither the locus of innovation nor exploitation need lie within companies' own boundaries.However, emulation of the open innovation approach transforms a company's solid boundaries into a semipermeable membrane that enables innovation to move more easily between the external environment and the company's internal innovation process. Indeed, the locus of innovation in these industries has migrated beyond the confines of the central $\mathrm{R} \& \mathrm{D}$ laboratories of the largest companies and is now situated among various startups, universities, research consortia and other outside organizations. This trend goes way beyond high technology other industries such as automotive, health care, banking, insurance and consumer packaged goods have also been leaning toward open innovation.

The results of research conducted by Gassmann and Enkel, (2000) can be summarized using the three core open innovation processes: "(1) The outside-in process: Enriching the company's own knowledge base through the integration of suppliers, customers and external knowledge sourcing can increase a company's innovativeness. (2) The inside-in process: earning profits by bringing ideas to market, selling and multiplying technology by transferring ideas to the outside environment. (3) The coupled process: coupling the outside-in and inside-out processes by working in alliances with complementary partners in which give and take is crucial for Success. All three the core processes represent an open innovation strategy, hut not all are equally important for every company" (Gassmann and Enkel, 2000). These three processes will form the theoretical framework upon which Open Innovation will he discussed in this paper.

\subsection{Outside-in Process, Inside-Out Process and Coupled Process}


The outside-in process involves a company's choice to invest in co-operation and integration with suppliers to gain relevant external knowledge. Practically, this is achieved through customer and supplier integration, listening posts at innovation, cluster, buying intellectual property and investing in global knowledge creation (Grassman and Enkel, 2000). Dyer, et al (1998), Boutellier and wagner (2002) and grassman and Enkel (2000) hold their views that inter-firm collaboration on supplier and customer relationship, knowledge scanning can significantly generate benefit in terms of differential relationship management. This is relevant in outsourcing, with source benefits as increase market acceptance of new products and increase in customers' subjective perception of the actual newness of a new product (Howe, 2006).

In the inside-out process, companies focus on externalizing knowledge and innovation in order to bring ideas to market faster than they can through internal development. A decision to change the locus of exploitation to outside the company's boundaries means generating profit by transferring ideas to other companies (Gassmann and Enkel, 2000). Commercializing ideas in different industries (cross industry innovation) and focusing on the inside-out process in open innovation can increase a company's revenue immensely. In this strategic sphere, firms can access to new knowledge, efficiency in managing capacity problem, concentration on core competencies, and sharing of costs. The inside-out open innovation strategy thus presupposes that, the locus of invention and innovation need not necessarily equal the locus of exploitation.

The coupled process of open innovation combines the outside-in process (to gain external knowledge) with the inside-out process ( to bring ideas to market). This brings about co-operation and integration in strategic networks. The result is an intensive exchange of knowledge involving mutual learning to gain distinctive competencies to improve the competitive position of the firms (Gassmann and Enkel, 2000). Herstad et al (2008) identify the reason for firms' collaborative behavior as: the necessity to facilitate the transfer of knowledge, gaining access to proprietory technology, access to skills, know-how and other facit knowledge, cost and risk sharing, and taking advantage of the economy of specialization. A precondition for working in co-operative innovation processes is the capacity to integrate external knowledge into a company's own knowledge into a company's own knowledge and technology, and to externalize it in order to enable the partner to learn. However, identification of the right partner capable of providing the needed competencies necessary to gain competitive advantage in the industry is a prerequisite for success in open innovation.

\section{The Organizational Structure Imperative}

Robbins and Sanghi (2006:428), opined that 'Organizational structures can shape attitudes and behaviour', adding that "there are six key elements that managers need to address when they design their organization structure". These according to them "are:work specialization, departmentalization, chain of command, span of control, centralization and decentralization, and formalization.Similarly, according to Dalton etal. (1978) "Organizational structure may be considered the anatomy of the organization, providing a foundation within which organizations function. The structure of organizations is believed to affect the behavior of organization members".

All organizations have structure. Hall (29) as quoted in Dalton etal (1978:1) suggests that structure serves two basic functions, each of which is likely to affect behaviour. First, structures are designed to minimize or at least regulates the influence of individual variations on the organization," and "structure is the setting in which power is exercised decisions are made, and in which the organization's activities arecarried out

Chandler's (1962) view on strategy and structure, as it also applies open innovation strategy is that strategy beggests structure. Thus, going by structure dilemma of Daft (20060, the suitability of structure must be relevant to change initiation (organic structure) and change implementation (mechanistic structure), both necessary at respective stages of innovation programme.

In a landmark study conducted in 20 British firms during the 1960s, Tom Burns and GM.Stalker identified two types of organizations mechanistic and organic. They observed that the mechanistic organization was characterized by: rules, procedures, a clear hierarchy of authority, centralized decision making, and the control of incoming and outgoing communications from the top and a tendency for information to be provided on a need to know basis. By contrast, the organic organization was characterized by: low formalization, rules and regulations were not written or if written down were ignored, and open and widely used communication patterns which incorporate horizontal, diagonal as well as vertical channels.

Burns and Stalker's research work stressed the belief that the organization could change its structure in relation to its environment. Thus, in a rapidly changingenvironment, an organization lends to change to organic form from the mechanistic form in order to remain competitive. The mechanistic form of organization structure is adopted when there is relative stability in the environment. Robbins ( )"these forms of organization structures represent two extremes of a continuum. While the mechanistic model is generally synonymous with the bureaucracy, the organic model looks more like the boundaryless organization. The relation of one form to the other is elastic. As such, an organization may oscillate from one end (mechanistic) to the other (organic) depending upon the nature of the environment and other factors like the overall strategy of the organization. organization size, and technology".

\section{The Organizational Culture Imperative}

It is widely acknowledged that corporate culture is a significant determinant of organization behaviour and performance. Organizational culture is a commonly held in-the-mind framework of organizational members. This framework 
contains basic assumptions and values. These basic assumptions and values are taught to new members as the way to perceive, think, feel, behave, and expect others to behave in the organization. Schein (1999) says that organizational culture is developed over time as people in the organization learn to deal successfully with problems of external adaptation and internal integration. It becomes the common language and the common background. So, culture arises out of what has been successful for the organization.

The notion of culture has been important in the study of organizational behaviour, in spite of the disagreements over some elements of definition and measurement; researchers seem to agree that culture may be an important factor in determining how well an individual fit an organizational context.

Robbins \&Sanghi (2006) opine that "there seems to be a wide agreement that organizational culture refers to a system of shared meaning held by members that distinguishes the organization from other organizations. This system of shared meaning is, on closer examination, a set of key characteristics that the organization values. The research suggests that there are seven primary characteristics that, in aggregate, capture the essence of an organizations culture. These characteristics are Innovation and risk taking, Attention to detail, Outcome Orientation, People orientation, Team orientation, Aggressiveness, and stability. Each of these characteristics exists on a continuum from low to high. Appraising an organization on these seven characteristics, then, gives a composite picture of the organizations culture. This picture becomes the basis for a feeling of shared understanding that members have about the organization, how things are done in it, and the way members are supposed to behave.

The culture of an organization is a representation of a common perception held by the members of an organization. Most large organizations have a dominant culture, which expresses the core values that are shared by a majority of the organization's members. This suggests that an organizations culture refers to the dominant culture. It is the macro view of the culture that gives an organization its distinct personality.

It thus follows that the organization orientation and paradigm on it pattern of innovation depends largely on its cultural orientation.

\section{How Open Innovation Relates To the Behaviour of Organizations}

Organizations do not seek to limit the number of minds focused on a problem to a selected few, instead they enlist thousands or millions with a passion to make a difference. Diversity of thought and access to a vast network of qualified minds become the valuable currency replacing the closed monolithic approaches that define many of today's organizations in Nigeria. Open innovation reaches outside the four walls of the Organization and attracts everyone eager to participate in advancing the cause- solving the problem.

Adopting open innovation demands a change from the traditional methods of value creation in organizations. Hitherto, organizations have kept their walls closed to input from outside the organization and the R\&D departments. They have also tried to hold back useful and otherwise ideas from the external environment. This change, especial lv in relation to the behaviour of organizations is to be affected in the structure and culture of the organizations since the behaviour of organizations is a function of the structure and culture, as established in the sections above.

\section{Open Innovation and Organizational Structure}

The traditional structure of the R\&D departments and organizations in general are usually mechanistic in their structural disposition. They are highly formalized, operate with limited information network, and are highly centralized. These departments function as a closed system, conducting and depending solely on their own research, with the idea that, as mentioned earlier, the process of creating new, innovative products and getting them out the door starts with tapping the most talented members of the R\&D team. They arrive at an idea, decide it is feasible, and move to determining the most effective way to develop it and bring it to market'.

A fundamental shift in innovation paradigms from closed to open innovation and advocates collaborative and open innovation strategies and open business models to take the full benefit from collaborating with external partners". An organizations structure is a means to help management achieve its objectives. Because objectives are derived from the organization's overall strategy, it is only logical that strategy and structure should be closely linked. More specifically, structure should follow strategy. If management makes a significant change in its organization's strategy, the structure will need to be modified to accommodate this change" Robbins \&Sanghi (2002). Thus, adopting open innovation i.e. the use of purposive inflows and outflows of knowledge to accelerate internal innovation, and expand the markets for external use of innovation, respectively', as a strategic option, will impact a change in the structure of the organization and that of the R\&D department. This will aid the achievement of organizational objectives.

From a mechanistic structure, (which is the traditional structural form of R\&D departments) usually characterized by centralization, narrow spans of control, formalization, downward communication, and little participation by lowlevelmembers, open innovation as a strategic option will demand a change to an organic structure which uses crosshierarchical and cross functional teams, operates with low formalization, possesses a comprehensive information network and involves high participation in decision making. 
The organic model is by its characteristics most compatible with the open innovation model. In practice, a convergence of the ideals of an organic structure and open innovation is most compatible, in that;

- Cross-functional teams can operate within and outside the R\&D department and the organization.

- Free flow of information is made possible by the demolition of walls that encapsulate the traditional innovation team.

- Wide spans of control are made possible through the use of information technology tools that make it possible for much more contributors to work on a project under one boss, as in the case of crowdsourcing.

- Decentralization is very much applicable since it possible for the 'final say about an innovation process may come from outside the organization through an informal channel, made possible by the outside in process of open innovation.

To this extent, a valid proposition can he made:

'Open innovation has a direct impact on the structure and by extension the behaviour of organizations".

This proposition is based upon the fact that open innovation demands a change from the traditional closed and mechanistic structures which have over the years been a mean of strategy execution, influenced employee behavior, and determined the response of organizations to specific conditions.

\section{Open innovation and organizational culture}

An earlier section of this paper has discussed organizational culture, this section attempts to relate open innovation to organizational culture. What all of these companies have in common, whether successful with innovation or not, is organizational culture that shape individual and group behavior, every organization has a culture: the issue is whether and how that culture inhibits or supports open innovation.

Today most leaders recognize that culture plays an important role in an organization's success. Accordingly, there are many popular strategies for shaping culture: training programs convey vision and values statements to help assimilate new employees:leadership development programs provide managers with tools fir becoming better leaders"; and change management initiatives help drive new structures and programs designed to increase organizational effectiveness

Organizational culture is an important factor related to encouragement of continuous improvement in organization. It takes in account all unwritten rules of conduct and behaviour of individuals and teams. The introduction of changes causes changing the organizational culture, which in turn means a gradual change in values of employees. Organizational culture is a system of thinking and ways of thinking which is common to people in the organization and distinguishes one organization from another. Organizational culture provides the organization with personality, we are like that, and we stand for it"(Vila 1994; Wheelen\& Hunger 1995 in Pipan\&Sokovic 2011) Open innovation, according to Serrat (2009) requires mind-sets and organizational cultures different from those of traditional (closed) innovation", although according to Scheimi, culture is the most difficult organizational attribute to change, outlasting organizational products, services, founders and leadership and all other physical attributes of the organization.

Although cultures are dynamic to the extent that changed circumstances can lead to the incorporation of new patterns of behaviour or ideologies, typically these are overlaid on existing core assumptions and thus a culture may exhibit what seem to be complex ambiguities or paradoxes (Trice \& Beyer 1993) until such time new behavioural adaptations to the environment give rise to a new belief system and set of core assumptions. This can be clearly seen in the case of egalitarianism, a value that is probably associated with a core assumption that life should he lived cooperativelythan competitively (Wilcoxon \&Milleti, 2000).

\section{Open Innovation and Inter-Organizational Interactions}

Given the foregoing, organizations must understand that adopting the principles of open innovation demands a cultural change. The cultural dimension of open innovation is highlighted by inter-organizational interaction which it does encourage. Hill \& Jones (2009) quoted in www.wikipedia.com/ organizationalculture, view organizational culture in terms of "the specific collection of values and norms that are shared by people and groups in an organization and that control the way they interact with each other and with stakeholders outside the organization." From the cultural perspective of open innovation, these values and norms should be modified to the extent that interactions extend to competitors, innovation blog contributors, and non-R\&D staff members. This is a purposeful form of interaction, which seeks to draw from the global hank of ideas and community of innovators because no company has a monopoly on useful knowledge anymore, since useful knowledge is becoming more and more widespread all over the world.

Innovation management has emphasized customers, suppliers and universities as important sources of innovation. Successful inventors have been shown to utilize multiple sources of information and ideas including, in-house R\&D, linkages to customers or other potential users of innovations, linkages to external network of competitors, suppliers, and linkages to other external sources ofscientific and technical information such as universities and research institutes. Both formal and informal external interactions have been found to provide the opportunity for thoughts, potential ideas and views to be exchanged and shared. The proactive search for technical and market inputs, as well as receptivity to information gained from external sources, are critical aspects of technology-based innovations. The accumulation of knowledge and the effective assimilation and application 
of this knowledge distinguishes innovative firms from their less successful counterparts. Thus, we can make the proposition that: "Open innovation influences the norms and values that determine inter-organizational interaction"

According to Kotter and Heskctt (1992), organizations with adaptive cultures perform much better than organizations with unadaptive cultures. An adaptive culture translates into organizational success; it is characterized by managers paying close attention to all of their constituencies, especially customers, initiating change when needed, and taking risks. An unadaptive culture can significantly reduce a firm's effectiveness, disablingthe firm from pursuing all its competitive/ operational options. From the above, we can propose that:Open innovation influences organizational posture on external adaptation."

\section{Open innovation and the culture of collectivism}

The open innovation paradigm promotes the culture of collective input to creating, improving, acquiring, sharing and profiting from knowledge. Hofstede identified four dimensions of culture in his study of national influences, one of which is Individualism vs. collectivism - individualism is contrasted with collectivism, and refers to the extent to which people are expected to stand up for themselves, or alternatively act predominantly as a member of the group or organization. Since open innovation promotes the culture of' collectivism, its application in the workplace that promotes individualism will naturally require for there to be a cultural change or adjustment, to the extent that collectivism is accepted and practiced. From the above, we can make a valid proposition, thus:Open innovation promotes the culture of collectivism"

\section{Discussion and Conclusion}

"Today, in many industries, the logic that supports an internally oriented, centralized approach to R\&D has become obsolete. Useful knowledge has become widespread and ideas must be used with alacrity. If not, they will be lost. Such factors create a new logic of open innovation that embraces external ideas and knowledge in conjunction with internal R\&D. This change offers novel ways to create value along with new opportunities to claim portions of that value". Chesbrough (2003). Accepting this change also means effecting changes in the structure and culture of the organization. Changes will have direct bearing on the extent to which the organizations can be made flatter and more organic, so as to be compatible with the principles of open innovation. Cultural adjustments in the areas of inter organizational interaction, external adaptation, and collectivism as opposed to the traditional seclusion and isolation. This behavioral change, impacted by the practice of open innovation will most certainly add great value to business organizations. Organizations can and should open up their boundaries to allow useful knowledge to flow in and out through the processes.

Developing Transparency -organizations should device means of information sharing and build trust with all of their employees and be sure to demand the same from them. It is here recommended for the organization to be made as flat (and non- hierarchical) as possible, look for opportunities to open up or share information beyond the basic transactional exchange of information with your outside world of customers and partners.

Taking advantage of networks - the society has become highly networked work place interactions. Thus, organizations should be aware of the value of these networks and encourage their employees to actively participate in professional networks, blogs, and other social media. There is a wealth of useful (and often) free information that is available.

Embrace community of practice - most successful networks have a sense of community or shared purpose. This implies a certain set of norms and expected behavior for members of a specific community. Interestingly enough, these communities can offer a great deal of insight and value to its members. On LinkedIn alone, there are over 3000 innovationrelated groups.

Competing and collaborating can be collaborators - although this may seem a little unusual to organizations, but the new world of innovation should force organizations to rethink what defines a competitor and ways in which they can work together. If you sell office productivity software, for example, are you competing against other software providers or is your bigger obstacle customer indifference towards your product? $P \& G$, for example, licensed a core plastic film technology to Clorox, a staunch competitor in certain markets, because $P \& G$ was no longer in the plastic film business. This would have been unimaginable fifteen years ago. Small companies can cooperate at certain levels to create entire eco-systems around new technology that can help raise the market opportunity for all involved. Twitter is a good example of a recent innovation in social media that has spawned an entire ecosystem of new services, all benefiting one another.

It is thus the contention implied in this paper that open innovation can abate the threats to organizational resilience and bring succor to firms in their endangered ecology.

\section{References}

i. Chandler A.D. (1962) Strategy and Structure: Chapters in the History of the American Industrial Enterprises, Cambridge, Mass: MTP Press.

ii. Chesbrough, F., Vanhaverbeke, W.and West, J., (2006)“Open innovation: Researching a New Paradigm. "Oxford University Press.

iii. Chesbrough, H., (2003) "The Era of “Open Innovation” MIT Sloan Management Review.Spring.

iv. Dalton, D., R, Fielding GJ Porter LW Spendolini, MJ and Todor WD. (1978) "Structure andPerformance: A Critical Review." Academy of Management Review. 
v. de Jong, J.PJ., W. Vanhaverbeke, T. Kalvet and H. Chesbrough (2008) "Policies for Open Innovation: Theory, Framework and Cases." Research Project Funded by VISION Era-Net, Helsinki: Finland.

vi. Fredberg, T., Elmquit, M., Ollia, S. (2008) "Managing Open Innovation Present Findings and Future Directions." VINNOVA- Verket Innovation Systems.

vii. Gassmann, O., Enkel, E. "Towards a Theory of Open Innovation: Three Core Process Archerypes. "(Publisher and date of publication unknown)

viii. Herstad, S. J., Bloch, C., Ebersberger, B. and van de Valde, E. (2008) "Open Innovation andGlobalization: Theory, Evidence and Implications." VINNOVA- Verket Innovation Systems.

ix. Hirota S. Kubo K, Miyajiina H, (2007) “Does Culture Matter?An Entrepreneurial Study on Japanese Firms" RIETI Discussion Paper Series 07.

x. Naqshbandi, M., M., Kaur, S. (2011) "A Study of Organizational Citizenship Behaviours, Organizational Structures and Open Innovation." International Journal of Business and Social Science Vol. 2 No. 6; Centre for Promoting Ideas, USA

xi. Nonaka, I., Takeuchi, H., (1995) "The Knowledge Creating Company: How Japanese Companies Create the Dynamics of Innovation ". New York: Oxford University Press.

xii. Robbins, S. P. Sanghi, S. (2002) “Organizational Behaviour” Dorling Kindersley (India) Pvt. Ltd.

xiii. Sawhney, M., Prandelli, E., (2000) "Communities of Creation: Managing Distributed innovation in Turbulent Markets." California Management Review Vol. 42. No.4 Summer.

xiv. Willcoxson, L., Milldft, B. (2000) "The management of organizational culture Australian" Journal of Management \& Organizational Behaviour, Volume 3, No. 2. 